\title{
The Relation of Physical Fitness and School Success of Children with Intellectual Disabilities
}

\author{
Miloš Popovići ${ }^{1,2}$, Hana Valkova ${ }^{3 *}$, Ružena Popović ${ }^{4}$ and Milan Dolga ${ }^{5}$ \\ ${ }^{1}$ Palacky University, Faculty of Physical Culture, Department of APA (master study), Olomouc, Czech Republic \\ ${ }^{2}$ University of Pristine/Kos. Mitrovica, Faculty of Sport and Physical Education, Leposavić, Kosovo, Serbia \\ ${ }^{3}$ Faculty of Sport Studies, Masaryk University, Brno, Czech Republic \\ ${ }^{4}$ University of Niš, Faculty of Sport and Physical Education, Niš, Serbia \\ ${ }^{5}$ Agency for Multivariate Data Analysis, "Smart-Line" - Novi Sad, Serbia
}

Submission: January 13, 2019; Published: February 08, 2019

*Corresponding author: Hana Valkova, Faculty of Sport Studies, Masaryk University, Brno, Czech Republic, Europe, United States

\begin{abstract}
The concept of the integrated development has served as the foundation of a number of theories of child intellectual and motor development. The learning of motor skills requires total physical and intellectual involvement for greatest efficiency. Purpose in this study was to establish the relation among motor competence and academic achievement. Physical Fitness Tests (PFT) items scores were transformed into standardized z-score and have not established significant correlation with other variables within total sample of participants. However, when separate analysis were conducted to examine differences between boys and girls, the relationship was evident in girls, but not in boys. General Conclusion derived from results of this study do not support constant link between PET variables and common indices of School success. Continued research is needed to gain more causal understanding of the relationship between physical fitness and cognition in children with intellectual disabilities.
\end{abstract}

Keywords: Special Education; Motor Competence; Intellectual disability; Relationship

Aim

Numerous studies revealed that during childhood the child's motor abilities improve with age [1,2]. Recently, a certain number of researches appeared dealing with the influence of gender to the structure of motor abilities. Based on the results of such researches, the structure of motor abilities does not change in the course of life, i.e. it is common for males and females [3,4]. However, in certain studies which are attempted to establish differences in motor abilities between boys and girls in early childhood, boys achieve better scores in majority of motor tests, particular in the tests of strength $[1,5,6]$.

Two major groups of factors that influence the child's development and account for gender differences in results of motor tasks are hereditary - biological and social factors $[7,8]$. Research on preschool children [9] showed that boys scored higher than girls in jumping tests (e.g. high jump, standing broad jump). Also, there are a few studies whose results showed the existence of significant differences of particular motor tests between boys and girls in early elementary school $[10,11]$. The boys achieved better in the following variables: speed of movement, explosive strength, body coordination, dynamic muscular endurance, static muscular endurance and aerobic endurance, whereas the girls scored better only in the variable of flexibility [10].

On the other hand there are other authors who have found no significant gender differences in motor abilities from the youngster's age of seven to that of twelve $[12,13]$. Since one of the principal tasks of physical education is development and reaching of optimal level of motor abilities of the pupils and taking into consideration the results of the researches so far, it can be said that planning of PE teaching is a complex procedure that attempts to objectify the regularities of entire children development [14]. The results of the research on preschool children show that the structure of motor area is almost identical for both genders, so it is possible to make one program of physical exercises that will be applied to both boys and girls regardless of the quantitative differences that exist between them [3]. Is it enough to have one program of physical exercises for both genders, and it is necessary to plan separate programs for development of motor abilities of boys and girls in the period of early school age?

As the contribution to the hypothesis that the efficacy in tests for the estimation of motor abilities is possible to explain 
with integral function of CNS, which represents as well the basis of intellectual functioning, speak the result of Reitana (1971) which point out that group of children with cerebral damage have as well weaker results in both cognitive and motor function, on the which base author made conclusion that the cognitive and motor abilities are in relation [15].

The basic goal of this current study is, therefore, to determine the developmental status of physical fitness in a group of individuals with intellectual disability (aged 11-16, and 16-21). Based on the previous research findings it is possible to state the logical hypothesis that positive and statistically significant age and gender differences will be estimated in motor development, between examined groups of students, using Physical Fitness Tests (PFT). Based on the above demonstrated approach, the concept and previous research, the aim of this research was to study gender and age differences in motor competences of elementary and secondary school students with mental deficiency.

\section{Physical and Motor Characteristics of Children with Intellectual Disabilities}

Children with intellectual disabilities differ least from children without intellectual disabilities in their motor characteristics. Although most children with intellectual disabilities display developmental motor delays, they are often related more to the limited attention and comprehension than to physiological or motor control deficit. As a group, children with intellectual disabilities walk and talk later, are slightly shorter, and usually are more susceptible to physical problems and illnesses than other children. In comparative studies, children with intellectual disabilities consistently score lower than children without intellectual disabilities on measures of strength, endurance, agility, balance, running speed, flexibility and reaction time.

Although many students with intellectual disabilities can successfully compete with their peers without intellectual disabilities, those students needing extensive or pervasive supports have a discrepancy equivalent to four or more years behind their peers without intellectual disabilities on tests of physical fitness and motor performance [16]. In investigation of relation of motor abilities and intellectual abilities one of the very first studies were that of Kulcinskia (1945) after Ismail [17] which established that the relation of intelligence and learning of basic motor tasks is higher, when the intellectual level of examinees is higher.

\section{Methods}

\section{Participants}

A cohort sample ( $\mathrm{N}=129$, Male-77; Female-52) of upper Elementary grades-classes (aged 11-12 to 15-17 years), and Secondary school pupils (aged 18 to 21 years) was derived from the global sample of Children, attending both Special Elementary and Secondary School in Nis (Serbia). A cohort sample (of smaller size) completed the Test of Physical Fitness (TPF) after Fjørtoft et al. [18]. The samples include children with intellectual disabilities in a wide range of socio-economic backgrounds and reflect the population of children attending special schools in this area. The mean chronological age of the children is between 11-17 years (in upper classes of Elementary school) and 18-21 years (in Secondary school). The sub-samples of examinees consist of both, the girls and boys; Table 1 .

Table 1: Presentation of the research samples size, according to the school level, gender, and class-level.

\begin{tabular}{|c|c|c|c|c|c|c|c|}
\hline \multirow{2}{*}{$\begin{array}{c}\text { Sample } \\
\text { Elementary }\end{array}$} & \multirow[t]{2}{*}{$\mathbf{N}$} & \multicolumn{4}{|c|}{ Global - larger size $(\mathrm{N}=282)$} & \multirow[t]{2}{*}{$\mathbf{N}$} & \multirow{2}{*}{$\begin{array}{c}\text { Sample } \\
\text { Secondary }\end{array}$} \\
\hline & & Male & Female & Male & Female & & \\
\hline V-VIII & 106 & 72 & 34 & 118 & 58 & 176 & I - IV \\
\hline \multirow[t]{2}{*}{ Total } & & \multicolumn{2}{|c|}{106} & \multicolumn{2}{|c|}{176} & & Total \\
\hline & & \multicolumn{4}{|c|}{282} & & \\
\hline Sample & $\mathbf{N}$ & \multicolumn{4}{|c|}{ Cohort - smaller size $(\mathrm{N}=129)$} & $\mathbf{N}$ & Sample \\
\hline Elementary & & Male & Female & Male & Female & & Secondary \\
\hline V-VIII & 77 & 51 & 26 & 38 & 14 & 52 & I - IV \\
\hline \multirow[t]{2}{*}{ Total } & & \multicolumn{2}{|c|}{77} & \multicolumn{2}{|c|}{52} & & Total \\
\hline & & \multicolumn{4}{|c|}{129} & & \\
\hline Sample & $\mathbf{N}$ & \multicolumn{4}{|c|}{ Sub-samples (N=129) } & $\mathbf{N}$ & Sample \\
\hline Elementary & & Male & Female & Male & Female & & Secondary \\
\hline $\mathrm{V}-\mathrm{VI}$ & 37 & 26 & 11 & 25 & 8 & 33 & I - II \\
\hline VII -VIII & 40 & 25 & 15 & 13 & 6 & 19 & III - IV \\
\hline Total & 77 & 51 & 26 & 38 & 14 & 52 & Total \\
\hline Elementary & & \multicolumn{2}{|c|}{77} & \multicolumn{2}{|c|}{52} & & Secondary \\
\hline Total & & \multicolumn{4}{|c|}{129} & & Total \\
\hline
\end{tabular}




\section{Instruments}

Test of Physical Fitness (TPF) is relatively a new test battery that aims to provide a reliable, objective quantification of children's physical fitness levels [18,19]. It consists of activities that are included in most children's everyday play activities, e.g. jumping, throwing, running and climbing. The battery consists of nine test items: (3) three based on jumping; (2) two on throwing; (1) one on climbing, and (3) three on running and. For that reason this battery is applicable for the participants with low motor competence, as were considered those with intellectual disabilities. The test battery is simple to set up and is not time demanding, which was also the reason for its selection.

The test item "climbing wall bars" was especially designed for the TPF. Test-retest correlation of total score of the TPF is high, 0.90 [18]. The construct validity of the test was 0.93 for girls and 0.89 for boys (Spearman's correlation). The validation was performed by an experienced physical education teacher who was asked to rank 10 girls and 10 boys in his class from lowest to highest physical fitness, according to his own implicit knowledge [19].

The nine test items are: (StBJ) Standing broad jump (cm); (2S7m) Jumping with the two feet a distance of $7 \mathrm{~m}$ as fast as possible $(0.1 \mathrm{sec})$; (1S7m) Jumping a distance of $7 \mathrm{~m}$ on one (preferred) (0.1sec); (TenB) Throwing a tennis ball with one hand (preferred) as far as possible (m); (MedB) Pushing a medicine ball $(1 \mathrm{~kg})$ with two hands as far as possible $(\mathrm{m})$; (Clmb) Climbing wall bars, crossing over two columns to the right, and down the fourth column as fast as possible (0.1sec); (10X5) Shuttle run (0.1sec); (R20m) Running $20 \mathrm{~m}$ as fast as possible (0.1sec); (MCT6) Reduced Cooper test (m).

\section{Additional Indicators - Criterion Variables of Special Interest for this Study}

Chronological age (AGE) of upper Elementary and Secondary school children (re-count at the end of the school year and provided in month);

Educational/Academic achievement/School success (SCSC) of upper Elementary and Secondary school children at the end of the school year and provided in points/grade-marks (real numbers with two decimals as the grades (5-excellent, 4very good, 3- good, 2- satisfactory/sufficient, 1- unsatisfactory/ un-sufficient)

Mental/Intellectual maturity (IQ) was provided by the School officials in charge (principal of the school, director of PE teachers; school psychologist, and social worker) (Table 2).

Table 2: Characteristics of the IQ (intellectual maturity) categories of participants.

\begin{tabular}{|c|c|c|}
\hline Code & Category & IQ \\
\hline $1-\mathrm{A}$ & Moderate impairments of intellectual development & 48 and less \\
\hline $2-\mathrm{B}$ & Intellectual development on the border between moderate and low impairments & $49-50$ \\
\hline $3-\mathrm{C}$ & Intellectual development in lower range of low impairments & $51-54$ \\
\hline 4-D & Intellectual development in the middle range of impairments (mild) & $55-65$ \\
\hline $5-\mathrm{E}$ & Intellectual development in the upper range of impairments & $66-68$ \\
\hline $6-\mathrm{F}$ & Intellectual development between low and borderline level of impairments & $69-70$ \\
\hline $7-G$ & Borderline level of intellectual development & $71-79$ \\
\hline 8-H & Below-average level of intellectual development & $80-89$ \\
\hline 9-I & Average level of intellectual development & $90-109$ \\
\hline
\end{tabular}

Data Processing: Study Results were processed using Basic and Descriptive Statistics (Mean; MIN and MAX; Standard Deviation; Coefficient of Variation\%; Interval), Analysis of Variance (t-test), ANOVA; Multivariate analysis of Variance (MANOVA), Pearson's Correlation Coefficient; Rang Coefficient of Correlation and Discriminative Analysis Methods (DISCRA) for Data Processing.

Test item sores were transformed into standardized score (z-scores) from the mean of the whole sample (n-129). Higher $\mathrm{z}$-scores indicate higher performance on the tasks. The total test score for each child was defined as the average z-score on all test items successfully performed by that child. Standardized z-scores were used for the correlation analysis only.

\section{Research Management}

The study was carried out in accordance with the Declaration of Helsinki. Prior to the gathering the data, the School Council and the parents were presented with the written information about the nature of the study, followed by signed permission from the participant's representative (principal) prior to their pupil's involvement in the study. The assessments of physical fitness took place in the school sports gym-hall during the timetabled Physical Education session for each particular class. Children were tested individually by PFT protocol.

\section{Results}

i. The whole research was conducted in frame of four thematic segments. There were analyzed differences among intellectual maturity sub-categories of individuals, between gender differences, and between grade-level differences, related to the segment of motor development in Special elementary and Secondary school students.

ii. The results data analysis, based on above mentioned analysis methods, produced statistically significant 
between-gender differences in favor of male sample of participants. Significant difference was established as well between grade-level sub-samples of Special Elementary and Secondary school participants $(\mathrm{p}=.000)$, and among different intellectual maturity-IQ sub-categories $(\mathrm{p}=.000)$.

iii. Special interest for this study was stated in regard of estimation the relationships among variables for estimation chronological age (Age/M), academic achievement (ScSs), intellectual maturity (IQ) and (PFT) motor development of participants, using Pearson's, Kendall's and Spearman's Correlation coefficient.

iv. The significant relationship was estimated between (Age/M) chronological age, and (ScSs) educational performance (at .05* level), and between IQ-Intellectual maturity and (ScSs) educational performance (at.01** level), with Kendall's (,416) and Spearman's (,537) Correlation coefficient.

v. Physical Fitness Test (PFT) items scores were transformed into standardized z-score (from the mean of the whole sample) and has not established significant correlation with other variables within total sample of individuals. Moreover, when separate analyses were con 7 ducted to examine differences between boys and girls, the relationship between ( $\mathrm{ScSs}$ ) academic achievement and (PFT) motor competence was evident in girls, but not in boys.

\section{Final considerations}

The whole research was conducted in frame of 4 thematic segments. There is analyzed between gender difference, between intellectual maturity and between grade-level difference, related to the motor development in elementary and secondary school students (C1), and the segment, related to the chronological age in month (Age/M) and academic achievement ( $\mathrm{ScSs}$ ) in elementary and secondary school participants with intellectual disabilities (C4). In 4 wholes is established difference and clearly defined border, between intellectual maturity, related to the motor development in elementary and secondary school participants with intellectual disabilities; between gender differences, related to the motor development in elementary and secondary school participants with intellectual disabilities; between grade-level differences, related to the motor development in elementary and secondary school participants with intellectual disabilities and differences between intellectual maturity, related to the chronological age and academic achievement of the participants.
The connection of the whole research to the one, in logical way, hierarchically ordered whole is important and possible. The contribution of the whole (thematic field) to the characteristics, and contribution of the variable to the characteristics within whole (inner) are parameters that clearly determine the hierarchy between thematic fields (wholes) as well as order of importance of variables. The connection of the whole research to the one, in logical way, hierarchically ordered whole is important and possible. The contribution of the whole (thematic field) to the characteristics, and contribution of the variable to the characteristics within whole (inner) are parameters that clearly determine the hierarchy between thematic fields (wholes) as well as order of importance of variables (Table 3).

Table 3: Contribution of the specific whole (segment) to the group characteristics.

\begin{tabular}{|c|c|c|c|}
\hline & Contribution \% & {$\left[\mathbf{C}_{\mathbf{1}}\right.$ )-C $\mathbf{4}$ )] } & Between \\
\hline 3 & 41.671 & Motor development & Grade-level \\
\hline 4 & 19.806 & $\begin{array}{c}\text { (Age/M) and (ScSs) } \\
\text { of students }\end{array}$ & $\begin{array}{c}\text { Intellectual } \\
\text { maturity }\end{array}$ \\
\hline 1 & 19.551 & motor development & $\begin{array}{c}\text { Intellectual } \\
\text { maturity }\end{array}$ \\
\hline 2 & 18.972 & motor development & Gender \\
\hline
\end{tabular}

Table 4: Contribution of the thematic field to the group characteristics.

\begin{tabular}{|c|c|c|c|}
\hline C & Contr. \% & Thematic field & Between \\
\hline 4 & 50.324 & $\begin{array}{c}\text { Chronological age and } \\
\text { academic achievement }\end{array}$ & $\begin{array}{c}\text { Intellectual } \\
\text { maturity }\end{array}$ \\
\hline 1 & 49.676 & Motor development & $\begin{array}{c}\text { Intellectual } \\
\text { maturity }\end{array}$ \\
\hline
\end{tabular}

On the base of the whole contribution (\%) to the characteristics of sub-samples, it is evident the highest (41.67\%) contribution of the thematic field motor development in El. and Sec. School participants (C3), to the grade-level characteristics, which means that characteristics of the sub-sample is clearly determined, and the distance between sub-samples is higher, in relation to the other distances, then follows: - the contribution of the thematic field (C4) chronological age and academic achievement (19.806\%), to the characteristics of intellectual maturity of participants, - contribution of the thematic filed motor development in El. and Sec. School participants (C1), to the characteristics of the intellectual maturity (9.551\%), and - the contribution of the thematic field motor development in Elementary and Secondary School participants (C2) to the gender characteristics is (18.972\%) the lowest (Table 4).

Table 5: The characteristics and contribution of the (PFT) variables within sub-samples.

\begin{tabular}{|c|c|c|c|c|c|}
\hline (PFT) & Grade (V-VI) & Grade (VII-VIII) & Grade (I-II) & Grade (III-IV) & Ctrb. \% \\
\hline MedB & Lowest & Smaller & The highest ${ }^{* 2}$ & Higher*2 & 32.36 \\
\hline $\mathrm{R} 20 \mathrm{~m}$ & Higher*2 & The highest $* 2$ & Smaller & Lowest & 32.36 \\
\hline TenB & Smaller & Lowest & The highest $* 2$ & Higher*2 & 11.89 \\
\hline $1 \mathrm{~S} 7 \mathrm{~m}$ & The highest*3 & Higher*1 & Smaller & Lowest & 8.98 \\
\hline StBJ & Lowest & Smaller & The highest*2 & Higher*2 & 7.79 \\
\hline
\end{tabular}




\section{Global Journal of Intellectual \& Developmental Disabilities}

\begin{tabular}{|c|c|c|c|c|c|}
\hline $10 X 5$ & Higher & The highest & smaller & Lowest & 6.61 \\
\hline hmg $\%$ & 62.16 & 65.00 & 84.85 & 89.47 & \\
\hline
\end{tabular}

Legend: (PFT) variables: MedB-pushing a medicine ball with two hands as far as possible; R20m-running $20 \mathrm{~m}$ as fast as possible; TenBthrowing a tennis ball with one hand; 1 S7m-jumping a distance of $7 \mathrm{~m}$ on one foot; StBJ-standing broad jump; 10X5- shuttle run; hmg \% homogeneity; ctrb. \% - contribution of the variable to the group characteristics.

Table 6: The characteristics and contribution of the additional variables (C4) to the characteristic of IQ-maturity sub-categories, related to the academic achievement and chronological age of students.

\begin{tabular}{|c|c|c|c|c|}
\hline$\left(\mathbf{C}_{\mathbf{4}}\right)$ & IQ (48-54) & IQ (55-70) & IQ (71-109) & Ctrb. \% \\
\hline ScSs & Smaller & Moderate*1 $^{*}$ & Higher*2 $^{*}$ & 83.99 \\
\hline AgeM & Smaller & Moderate & Higher*1 & 16.01 \\
\hline hmg \% & 67.52 & 60.91 & 69.09 & \\
\hline
\end{tabular}

Legend: AgeM-age; and ScSs-school success; hmg\% - homogeneity; ctrb. \% - contribution.

Table 7: The characteristics and contribution of the variable to the characteristic of IQ- maturity sub-categories, related to the motor development of students.

\begin{tabular}{|c|c|c|c|c|}
\hline (PFT) & IQ (48-54) & IQ (55-70) & IQ (71-109) & Ctrb. \% \\
\hline R20m & Moderate*1 $^{*}$ & Higher*2 & Smaller & 38.21 \\
\hline Clmb & Higher*2 & Moderate*1 & Smaller & 26.42 \\
\hline TenB & Moderate & Smaller & Higher*2 & 12.74 \\
\hline $1 S 7 m$ & Higher*2 & Moderate*1 & Smaller & 11.79 \\
\hline $10 X 5$ & Higher*1 & Moderate & Smaller & 8.49 \\
\hline $2 S 7 m$ & Higher*1 & Moderate*1 & Smaller & 2.36 \\
\hline hmg \% & 64.29 & 48.00 & 69.57 & \\
\hline
\end{tabular}

Legend: (PFT) variables: R20m-running $20 \mathrm{~m}$ as fast as possible; Clmb-climbing wall bars, crossing over two columns to the right, and down the fourth column as fast as possible; TenB-throwing a tennis ball with one hand; $157 \mathrm{~m}$-jumping a distance of $7 \mathrm{~m}$ on one foot 10X5- shuttle run; $2 \mathrm{~S} 7 \mathrm{~m}$-jumping on two feet a distance of $7 \mathrm{~m}$; $\mathrm{hmg}$ $\%$ - homogeneity; ctrb. \% - contribution of the variable to the group characteristics

Table 8: The characteristics and contribution of the (PET) variable to the gender characteristic, related to the motor development of students.

\begin{tabular}{|c|c|c|c|}
\hline (PFT) & Male & Female & Ctrb. \% \\
\hline MedB & Higher*1 & Smaller & 28.24 \\
\hline $10 X 5$ & Smaller & Higher*1 & 21.37 \\
\hline
\end{tabular}

\begin{tabular}{|c|c|c|c|}
\hline Clmb & Smaller & Higher*1 & 17.56 \\
\hline 2S7m & Smaller & Higher*1 $^{*}$ & 16.79 \\
\hline TenB & Higher*1 & Smaller & 10.69 \\
\hline R20m & Smaller & Higher*1 $^{*}$ & 5.34 \\
\hline hmg \% & 64.04 & 77.50 & \\
\hline
\end{tabular}

Legend: (PFT) variables: MedB-pushing a medicine ball with two hands as far as possible; 10X5- shuttle run; Clmb-climbing wall bars, crossing over two columns to the right, and down the fourth column as fast as possible; $2 \mathrm{~S} 7 \mathrm{~m}$-jumping on two feet a distance of $7 \mathrm{~m}$; TenBthrowing a tennis ball with one hand; R20m-running $20 \mathrm{~m}$ as fast as possible; hmg\%-homogeneity; ctrb.\%-contribution.

Observing the results of the applied analysis, related to the IQ-maturity, it is evident that the contribution of the thematic field chronological age (Age/M) and school success ( $\mathrm{ScSs}$ ) of students(C4) to the group characteristics is (50.324\%), and the contribution of the thematic field motor development to Special El-, and Sec-School students (C1) is (49.676 \%) (Tables 5-8).

\section{Correlations}

Table 9: Descriptive Statistics - Total sample.

\begin{tabular}{|c|c|c|c|}
\hline Descriptive Statistics & Mean & Std. Deviation & $\mathbf{N}$ \\
\hline AGE/M & 192,5194 & 29,1859 & 129 \\
\hline IQ & 4,0078 & 1,8092 & 129 \\
\hline SCSS & 3,7670 &, 9137 & 129 \\
\hline Z & $-1,5504 \mathrm{E}-04$ & 2,2774 & 129 \\
\hline
\end{tabular}

Legend: AGE/M -Chronological Age of Participants, presented in months; IQ - Mental maturity; SCSS - School Success, presented in decimal marks; $Z$ - Physical Fitness Test (recalculated to the one Z-et score)

(Tables 9 \& 10) Relationships are established between AGE/M and SCSS, and IQ - SCSS; Physical Fitness Test - Z-et value has not established any kind of correlation with other variables.

Table 10a: Special Elementary and Secondary school students - Total sample.

\begin{tabular}{|c|c|c|c|c|c|}
\hline & Correlations & AGEM & IQ & SCSS & $\mathrm{Z}$ \\
\hline \multirow{5}{*}{ AGEM } & Pearson Correlation & 1,000 &,- 097 &,- 185 &,- 094 \\
\hline & Sig. (2-tailed) & , & ,273 & 036 & ,289 \\
\hline & $\begin{array}{l}\text { Sum of Squares and } \\
\text { Cross-products }\end{array}$ & 109032,202 & $-656,519$ & $-632,267$ & $-800,610$ \\
\hline & Covariance & 851,814 & $-5,129$ & $-4,940$ & $-6,255$ \\
\hline & $\mathrm{N}$ & 129 & 129 & 129 & 129 \\
\hline \multirow{5}{*}{ IQ } & Pearson Correlation &,- 097 & 1,000 &, 503 &,- 044 \\
\hline & Sig. (2-tailed) & 273 & , & , 000 & 618 \\
\hline & $\begin{array}{l}\text { Sum of Squares and } \\
\text { Cross-products }\end{array}$ & $-656,519$ & 418,992 & 106,463 & $-23,380$ \\
\hline & Covariance & $-5,129$ & 3,273 & 832 &,- 183 \\
\hline & $\mathrm{N}$ & 129 & 129 & 129 & 129 \\
\hline
\end{tabular}




\section{Global Journal of Intellectual \& Developmental Disabilities}

\begin{tabular}{|c|c|c|c|c|c|}
\hline \multirow{5}{*}{ SCSS } & Pearson Correlation &,- 185 & ,503 & 1,000 &,- 027 \\
\hline & Sig. (2-tailed) & ,036 & ,000 & , & ,764 \\
\hline & $\begin{array}{l}\text { Sum of Squares and } \\
\text { Cross-products }\end{array}$ & $-632,267$ & 106,463 & 106,867 & $-7,108$ \\
\hline & Covariance & $-4,940$ & ,832 & ,835 & $-5,553 \mathrm{E}-02$ \\
\hline & $\mathrm{N}$ & 129 & 129 & 129 & 129 \\
\hline \multirow{5}{*}{$\mathrm{Z}$} & Pearson Correlation &,- 094 &,- 044 &,- 027 & 1,000 \\
\hline & Sig. (2-tailed) & ,289 & ,618 & ,764 & , \\
\hline & $\begin{array}{l}\text { Sum of Squares and } \\
\text { Cross-products }\end{array}$ & $-800,610$ & $-23,380$ & $-7,108$ & 663,903 \\
\hline & Covariance & $-6,255$ &,- 183 & $-5,553 \mathrm{E}-02$ & 5,187 \\
\hline & $\mathrm{N}$ & 129 & 129 & 129 & 129 \\
\hline
\end{tabular}

${ }^{*}$ Correlation is significant at the 0.05 level (2-tailed)

${ }^{* *}$ Correlation is significant at the 0.01 level (2-tailed)

Table 10b: Special Elementary and Secondary school students - Total sample.

\begin{tabular}{|c|c|c|c|c|c|c|}
\hline & & Correlations & AGEM & IQ & SCSS & $\mathrm{Z}$ \\
\hline \multirow{12}{*}{ Kendall's tau_b } & \multirow{3}{*}{$\mathrm{AGE} / \mathrm{M}$} & Correlation Coefficient & 1,000 &,- 086 &,- 133 &,- 060 \\
\hline & & Sig. (2-tailed) & , & ,186 & ,030 & ,319 \\
\hline & & $\mathrm{N}$ & 129 & 129 & 129 & 129 \\
\hline & \multirow{3}{*}{ IQ } & Correlation Coefficient &,- 086 & 1,000 & ,416 &,- 027 \\
\hline & & Sig. (2-tailed) & ,186 & , & ,000 & ,675 \\
\hline & & $\mathrm{N}$ & 129 & 129 & 129 & 129 \\
\hline & \multirow{3}{*}{ SCSS } & Correlation Coefficient &,- 133 & ,416 & 1,000 &,- 021 \\
\hline & & Sig. (2-tailed) &, 030 & ,000 & , & ,733 \\
\hline & & $\mathrm{N}$ & 129 & 129 & 129 & 129 \\
\hline & \multirow{3}{*}{$\mathrm{Z}$} & Correlation Coefficient &,- 060 &,- 027 &,- 021 & 1,000 \\
\hline & & Sig. (2-tailed) & ,319 & ,675 & ,733 & , \\
\hline & & $\mathrm{N}$ & 129 & 129 & 129 & 129 \\
\hline \multirow{12}{*}{ Spearman's rho } & \multirow{3}{*}{ AGEM } & Correlation Coefficient & 1,000 &,- 125 &,- 194 &,- 099 \\
\hline & & Sig. (2-tailed) & , & ,159 & 027 & ,265 \\
\hline & & $\mathrm{N}$ & 129 & 129 & 129 & 129 \\
\hline & \multirow{3}{*}{ IQ } & Correlation Coefficient &,- 125 & 1,000 &, 537 &,- 035 \\
\hline & & Sig. (2-tailed) & ,159 & , & 000 & ,693 \\
\hline & & $\mathrm{N}$ & 129 & 129 & 129 & 129 \\
\hline & \multirow{3}{*}{ SCSS } & Correlation Coefficient & -194 & ,537 & 1,000 &,- 027 \\
\hline & & Sig. (2-tailed) & 027 & ,000 & , & ,762 \\
\hline & & $\mathrm{N}$ & 129 & 129 & 129 & 129 \\
\hline & \multirow{3}{*}{$\mathrm{Z}$} & Correlation Coefficient &,- 099 &,- 035 &,- 027 & 1,000 \\
\hline & & Sig. (2-tailed) & ,265 & ,693 & ,762 & , \\
\hline & & $\mathrm{N}$ & 129 & 129 & 129 & 129 \\
\hline
\end{tabular}

${ }^{*}$ Correlation is significant at the .05 level (2-tailed)

${ }^{* *}$ Correlation is significant at the .01 level (2-tailed).

\section{Conclusion}

Based on the obtained results, applied analyses and their interpretation, the following conclusions could be stated:

a. C1 - Evaluating motor development using MANOVA (.002) and DISCRA (.002) analysis, statistically significant differences were estimated among 3 sub-categories of intellectual maturity, related to the (PFT) Physical Fitness Test items;

b. C2 - Evaluating motor development using MANOVA (.001) and DISCRA (.001) analysis, statistically significant gender differences were estimated, between two subsamples (Male/Female), related to the (PFT) variables; 
c. C3 -Evaluating motor development using MANOVA (.000) and DISCRA (.000) analysis, statistically significant grade-level differences were evidenced among classes, related to (PFT) variables;

d. C4 -Evaluating chronological age (Age/M), and academic achievement (ScSs) in Special elementary and secondary school participants with intellectual disabilities, using MANOVA (.000) and DISCRA (.000) analysis, statistically significant differences are estimated among 3 sub-categories of intellectual maturity. Difference is not estimated (only latent) at: chronological age/calendar (.323), with discrimination coefficient: school success (.257), age in month (.049).

While alternative hypothesis A1, A2, A3 and A4 were stated with positive connotation and expectation of significant differences between elementary and secondary school participants, and observed research fields, which were confirmed in majority of cases, it is possible to conclude, with respect of some methodological limitations, that estimated differences point up on clearly defined borders and specific groups characteristics, and homogeneity of evaluated research segments.

General conclusion, derived from results of this study, provided within Special Education Students in upper level of Elementary, and Secondary School grades do not support a link between Physical Fitness Test and common indiᄀces of academic achievement, such as average of various educational subjects' marks (grade-points). Specifically, in elementary school students, a modest association was observed among the physical fitness variables and academic achievement scores. Moreover, when separate analyses were con $\neg$ ducted to examine differences between boys and girls, the relationship between academic achievement and (PFT) was evident in girls but not in boys.

Continued research is needed to gain a more causal understand $\neg$ ing of the relationship between physical fitness and cognition in children with intellectual disabilities. Future research should address and explain which parameters of physical fitness and activities obtain the greatest cognitive benefits, examine the effects of physical activity and fitness by cohorts, and investigate which moderators have the greatest impact on student cognition and education performance.

\section{Limitations}

Despite the contribution regarding the relationship of physical fitness to academic achievement, several limitations of the study warrant mention. First, as discussed, student motivation may account for a portion of the variance explained in the rela $\neg$ tionship between physical fitness and academic performance. Second, the utilization of field-test measures of physical fitness, although administered by researchers, have a restricted evaluation of fitness in children. Finally, the sample was not random, and therefore the findings from this study may not be generalized to other populations.

The cross-sectional design of the present study clearly limits the conclu $\neg$ sions that can be drawn, and one cannot attribute causation to any of the ob $\urcorner$ served relationships. Academic performance tends to decline for many youths, particularly females, during adolescence.

The findings of this study suggest that participation in physical ac $\neg$ tivities, and especially vigorous physical activities, may help some youth traverse this difficult period. Alternatively, it may be that many youth face barriers to participation, and that it is mainly those with strong self-esteems that participate. Ei $\neg$ ther way, the results call for measures that would increase access to physical ac $\neg$ tivities for all adolescents, and especially females. The finding that higher levels of physical activity had relatively small ef $\neg$ fects on academic achievement is consistent with the findings of previous cross-sectional and longitudinal studies. However, our measure of physical activ $\neg$ ity provides only a rudimentary account of the quality and quantity of students' physical activity.

In addition, our measures had strengths and limitations. Academic achievement was not assessed through a standardized test, in regard to avoid any potential rater bias that might have been introduced while academic achieve $\neg$ ment had been based on ratings by classroom teachers.

\section{References}

1. Benefice E, Fouere T, Malina RM (1999) Early nutritional history and motor performance of Senegales children, 4-6 years of age. Ann Hum Biol 26: 443-445.

2. Davies PL, Rose JD (2000) Motor skills of typically developing adolescents: Awkwardness or improvement? Phys Occup Ther Pediatr 20: 19-42.

3. Fratrić F, Rubin P (2006) Qualitative differences between motor status of boys and girls at the age of 4-7: In Novi Sad, Collection of papers, Anthropological status and physical activity of children and youth. Novi Sad, p. 51-56.

4. Marsh HW (1993) The multidimensional structure of physical fitness: Invariance over gender and age. Res Q Exerc Sport 64: 256-273.

5. Backman E (1988) Methods for measurement of muscle function: Methodological aspects, reference values for children, and clinical applications. Scand J Rehabil Med Suppl 20: 9-95.

6. Zurc J, Pišot R, Strojnik V (2005) Gender differences in motor performance in 6.5 year-old children. Kinesiologica Slovenica 11: 90-104.

7. Haywood KM, Getchell N (2001) Life span motor development, Human Kinetics, Canada.

8. Hottinger W (1983) Early childhood. In C.B. Corbin (Ed.), A textbook of motor development Wm. C. Brown Company Publishers: Iowa, United States p. 26-30.

9. Pišot R (2000) The analysis of the structure of six-and-a-half year old children's motor space in the light of its development as a whole. Acta Universitatis Caroline Kinanthropologica 36: 67-78.

10. Pejčić A, Malacko J (2005) The ontogenetic development of morphological characteristic and motor abilities of boys and girls in early elementary school. Kinesiologica Slovenica 11: 42-55. 
11. Rodić N (1999) Effects of P.E. on differentiation of flexibility and power of pupils at lower levels of elementary school according to gender and age, Collection of papers, $2^{\text {nd }}$ and $3^{\text {rd }}$ international symposium. Effects of different models of teaching on psychosomatic status of children and youth, Novi Sad p. 21-26.

12. De Oreo K, Keogh J (1983) Performance of fundamental motor tasks. In C.B. Corbin (Edn), A textbook of motor development. Wm. C. Brown Company Publishers: Iowa, United States p. 76-91.

13. Kukolj M (1999) Motor functions as basis for planning and programming of P.E. teaching. Nastava i vaspitanje XLVIII 1-2: 133-139.

14. Valkova H (2009) Adapted Physical Activities-Challlenge for Research. Proceedings of Abstracts of International Conference "Sport and Quality of Life 2009", $5^{\text {th }}-6^{\text {th }}$ November, Brno, Czech Republic, Europe pp. 124.

This work is licensed under Creative Commons Attribution 4.0 License

DOI: $10.19080 /$ GJIDD.2019.06.555682
15. Gredelj M, Metikoš D, Hošek A, Momirović K (1975) Model of hierarchic structure of motor abilities, the results obtained using a neoclassical method for estimating latent dimensions. Kineziologija 5(1-2): 18-19.

16. Winnick JP (2005) Adapted Physical Education and Sport. Appendix C, Brockport Physical fitness test pp. 545-547.

17. Ismail AH (1976) Povezanost između kognitivnih, motoričkih i konativnih karakteristika. (Relationship Between Intellectual, Motor and Conative Characteristics), Kineziologija 6(1-2): 47.

18. Fjørtoft I, Pedersen AV, Sigmundsson H, Vereijken B (2003) Testing Children's Physical Fitness - Developing a New Test for 4-12 Years Old Children. Report (IS-1256) The Norwegian Social and Health Ministry, Oslo, Norway.

19. Haga M (2008) Physical fitness in children with movement difficulties. Physiotherapy (94)3: 253-259.

\section{Your next submission with Juniper Publishers will reach you the below assets}

- Quality Editorial service

- Swift Peer Review

- Reprints availability

- E-prints Service

- Manuscript Podcast for convenient understanding

- Global attainment for your research

- Manuscript accessibility in different formats

( Pdf, E-pub, Full Text, Audio)

- Unceasing customer service

Track the below URL for one-step submission https://juniperpublishers.com/online-submission.php 